\title{
"The Words Disappeared When Faced with Real Life Situations": Communication Difficulties of Non-Native Speakers of Arabic in the Sultanate of Oman
}

\author{
Fatma Yousuf Al-Busaidi ${ }^{1, *}$ \\ ${ }^{1}$ Department of Curriculum \& Instruction, College of Education, Sultan Qaboos University, \\ Sultanate of Oman \\ *Corresponding author: E-mail: fbusaidi@squ.edu.om
}

Received: April 5, 2019

Accepted: May 4, 2019 Published: June 7, 2019

doi:10.5296/ije.v11i2.14616

URL: https://doi.org/10.5296/ije.v11i2.14616

\begin{abstract}
The learning of Arabic as a foreign language (AFL) is increasing around the world. Even so, non-native speakers learners of Arabic face an array of communication difficulties. The present study is intended to explore some of the possible communication difficulties encountered by adult learners of Arabic in the Sultanate of Oman. An interpretive approach was adopted for the study, using in-depth interviewing and participants' diaries. The findings of the study revealed that non-native Arabic speakers face four distinct difficulties when they attempt to communicate in Arabic. These difficulties are categorized as: putting thoughts into words, maintaining continuous speaking, pronunciation-related issues and applying grammar in their speech. These findings call for improved teaching programs, bridging the gap between classroom teaching activities and authentic life situations and the placing of parallel emphasis on both standard (written) Arabic and vernacular spoken Arabic in its different contextual communities. It is recommended that more studies investigating the dichotomy between colloquial Arabic varieties and standard Arabic should be undertaken.
\end{abstract}

Keywords: Communication Difficulties, Non-Native Speakers, Arabic Language, Sultanate of Oman 


\section{Introduction}

The Arabic language is considered as one of the most important languages worldwide since it ranks sixth in the number of speakers. Dweik and Shallakh (2015) estimated that Arabic is spoken by about 289 million native speakers and approximately 256 million non-native speakers around the world. Taha (2007) indicated that President Bush, in 2006, launched an initiative called the "National Security Language Initiative" that aimed to increase the number of students studying "critical need" languages, among which was Arabic. Hence, learning Arabic has increasingly gained significant attention and numerous researchers acknowledge the necessity of learning Arabic (Blake \& Shiri, 2012; Yani, Ahmed, Sahrir, Muritala, \& Kama, 2014 among others).

Previous studies have indicated a multiplicity of learners' goals when learning Arabic. For example, non-Arab Muslims learn the language to understand the Holy Quran and to enable them to perform Islamic practices; prayers, hajj (pilgrimage), and other acts of Islamic worship (Dweik \& Abu-Irmies, 2015; Wekke, 2015; Yaakub, 2012; Yani et al., 2014 among others). In addition, some learners aim to fulfil an academic program requirement (Aladdin, 2013; Dweik \& Abu-Irmies, 2015; Wekke, 2015), while others are interested in learning about Arabic culture and in using Arabic for social and business communication (Yani et al., 2014). Some learn it when they seek a job in agencies or workplaces that operate in the Arab world (Dweik \& Abu-Irmies, 2015). In his study of learning Arabic in the USA, Palmer (2007) reported that $88 \%$ of the students studied Arabic because they wanted to interact with native speakers.

Despite the fact that interaction in the target language and its constant application in speaking and writing are known to lead to effective acquisition (Yani et al., 2014), learners of Arabic face a number of obstacles that limit their communicative competence and delay their attainment of proficiency (Bin Samah et al., 2016; Dweik \& Shallakh, 2015). Dajani, Mubaideen and Omari (2014) found that many learners of Arabic lack communicative competence, even after extreme effort, and this may lead them to give up learning and using the language after a year or two of study.

Previous studies have confirmed that the communication problems faced by learners of ASL are due to several reasons. Examples of such difficulties include, but are not limited to, lack of opportunities to communicate in Arabic; the distance between the Standard Arabic usually taught in classroom settings and the non-standard Arabic used in natural settings; Arabic pronunciation, characteristics of the language and lastly the inability to express one's own thoughts (Bin Samah et al., 2016; Dweik \& Shallakh, 2015).

In an attempt to study the demotivating factors that impact the Arabic language classrooms of non-Muslim Malaysians, Aladdin (2013) concluded that the lack of opportunities to communicate in Arabic was one contributing factor to learners' demotivation and poor speaking skills. Similarly, Haron, Ahmed, Mamat, Ahmad and Rawash (2016) interviewed 14 Malay Arabic learners to find out the challenges they faced when learning to speak in Arabic. Their findings revealed that those learners faced internal obstacles such as knowledge and skill, and external obstacles like the lack of a supportive environment and the lack of 
opportunities to speak Arabic. The findings of Redkin and Bernikova (2016) similarly confirmed that when students try to communicate in Arabic, they face several difficulties such as the absence of opportunities to practise the language learned in the classroom.

It is also argued that the difficulties students face in learning to communicate in Arabic could be due to the differences between the Standard Arabic and the spoken Arabic that is often referred to as dialects. Despite the fact that spoken Arabic is less prestigious than Standard Arabic, it is the language used for daily communication (Palmer, 2007). Dweik and Al-Shallakh (2015), for example, conducted a research study for the purpose of identifying the difficulties non-natives face in learning Arabic at two Jordanian public universities. Their findings indicated that non-natives face difficulties in learning Arabic due to the different varieties of Arabic. Almelhes (2016) and Palmer (2007) stated that students' communication difficulties result from the fact that the language used for every day communication in the Arabic speaking world is not the formal Arabic which students learn in the classroom. Additionally, Al-Busaidi (2015) concluded that the big gap between spoken Arabic dialects and Standard Arabic continues to represent an obstacle to interaction in Arabic. If learners of Arabic hope to integrate in an Arabic-speaking community, they should be introduced to the appropriate variety of spoken Arabic (Palmer, 2007).

Added to that, many researchers contend that foreign adult learners of Arabic are likely experience pronunciation difficulties that cause communication break down or hinder speech intelligibility (Shehata, 2017; Zielinski, 2008). Almelhes (2016) for instance, reported that many non-native Arabic speakers experience pronunciation difficulties particularly with eight consonant sounds ( $(\dot{\varepsilon}$,, $)$. These consonant letters are very often absent from languages such as English. Thus, learners of Arabic are likely to experience difficulties when producing such letters.

Furthermore, Awang, Mohamed and Sulaiman (2013) found that learners of Arabic tend to face difficulties when framing their thoughts. Yaakub (2012) linked this to a lack of the vocabulary required to take students through communication activities. Similarly, Shaalan, Magdy and Fahmy (2015) stated that in the case of Arabic language, non-native learners feel confused by Arabic lexical rules (morphological and phonological rules). They therefore find it challenging to express their thoughts clearly. Moreover, Al-Busaidi (2015) suggests that inadequate introduction to Arabic culture in AFL classroom instructions can be a pitfall for some programmes. The absence of cultural schema hinders overall comprehension, including speaking.

\section{Statement of the Problem}

Communication using the target language is important for any language learners who wish to practise what they have learned, to improve their language skills and to gain cultural knowledge by engaging in communicative situations. Speaking is a productive skill and a critical constituent of any foreign language proficiency. It plays a substantial role in foreign language acquisition. The ability to interact fluently in spoken communication is the ultimate 
goal for most foreign language learners. However, learning to speak in a second/other language can be a hard task, especially for adult learners (Haron, 2013; Haron et al., 2016).

Speakers of AFL face numerous difficulties that impede their communication and deter their language development. Most of the studies that examined the speaking difficulties of learners of Arabic have been conducted in countries such as the USA, Malaysia or Turkey where Arabic is not the native language. The hindrances faced by learners when trying to communicate in Arabic in those countries may or may not resemble the problems faced by learners of Arabic in countries where Arabic is the language of the majority of the population. The peculiarity of learning Arabic by non-native Arabic speakers in a country like Oman, where Arabic is the official spoken language, requires research, if only to discover the types of difficulties encountered by such learners.

Previous research studies have primarily concentrated on the teaching of Arabic as a first language, without paying much attention to AFL. There are few studies in the field of AFL even though learning Arabic by non-Arab speakers has gained popularity (Wekke, 2015). Teaching ASL/AFL, for example, has not been guided by extensive research and thus we know little about the difficulties students face in different learning environments (Hansen, 2010; Hayes - Harb \& Durham, 2016; Raish, 2015). In the field of AFL studies, very little is known andvery little research has been conducted regarding Arabic pronunciation (Shehata, 2017). Similarly, spoken Arabic, dialects are not generally taught and they are not mentioned in some large scale research studies (Palmer, 2007). This has led researchers such as Ryding (2006) to call for urgent research in the AFL field to understand the processes involved in learning Arabic and to examine learners' difficulties.

Despite the fact that some previous research studies (e.g. Al-Busaidi, 2015, El-Omari \& Bataineh, 2018; Hamidin, 2019; Haron et al., 2016; Poyas \& Bawardi, 2018) have explored the difficulties faced by learners of Arabic, a critical review of these studies indicates a pressing need for further studies. For instance, these research works have studied difficulties in general, but have not focussed on communication-related difficulties, particularly speaking. The development of all four language skills is outlined as one of the goals of Arabic instruction in many Arabic programmes. Nonetheless, a closer analysis uncovers the lack of a systematic approach to the teaching of speaking, since there are no activities or materials that specifically address the development of this skill (Awang et al., 2013, Haron, 2013; Haron et al., 2016).

In the Omani context, and to the best of the researcher's knowledge, no attempt has been made to explore the communication difficulties of non-Arabic speakers. This study is therefore intended to provide an overview of the speaking difficulties faced by non-native Arabic learners in the Sultanate of Oman. Additionally, the study aims to describe the factors that might affect learners' communication skills. By understanding the difficulties learners face, it is hoped that teachers and other educators will be able to improve their instruction and methods of teaching Arabic and thus encourage even more students to learn Arabic. Hopefully, the study will add to the existing literature in this particular area and it will contribute to the planning and the enhancement of Arabic language programmes in Oman. 


\section{Research Methodology}

A qualitative approach was employed for the study design in collecting, analysing and interpreting the data. It is believed that in-depth understanding can be achieved by approaching research problems qualitatively. The following points shed more light on the study participants and the instruments used for data collection. This is followed by analysis of the collected data.

\subsection{Participants}

Participants of the present study were 19 adult learners ranging from 32 and 52 years old. They came from seven different cultural backgrounds; India, Sweden, England, the Netherlands, Turkey, France and Italy. They were Bachelor and Master degree holders and sixteen of them were full time employees either as lecturers or managers in well-known companies or they were employed at embassies in Oman. In other words, they were in Oman mainly for work purposes.

These 19 participants (11 male and 8 female) studied Arabic at the same private institute in Oman. In fact, there are only three institutions that offer Arabic language courses in Oman and only one institute agreed to take part in this study. The students selected for the study were at level three and so they probably had sufficient knowledge and experience to be comfortable when sharing their thoughts and insights about learning Arabic language. They would certainly be better aware of the specific challenges that they faced, and were still facing, throughout their experience of learning Arabic than beginners with little knowledge and experience. The 19 participants represented an adequate sample size considering the main objective of the study. This qualitative study was not intended to reach a generalization of the sort of speaking difficulties students face when learning Arabic. It rather aimed to gain an in-depth understanding of each participants' experience and of the challenges that $\mathrm{s} / \mathrm{he}$ had encountered when learning Arabic.

\subsection{Data Collection}

The researcher collected the research data via a semi-structured interview and from participants' diaries. Below is a detailed description of each instrument.

\subsubsection{Semi-Structured Interviews}

Semi-structured interviews allow in-depth information to be gathered from informants, while at the same time preventing divergence from the core focus of the research purpose or rambling (Newcomer, Hatry \& Wholey 2015). Each participant was interviewed twice. At the first interview the researcher checked the credibility of the data collected, while the second interview acted as a supplement for the first one. During the second interview, the researcher was also able to ask the students new questions as they emerged from their diaries. In general, the informants provided more detailed information during the second interview possibly due to the knowledge they had gained from the first interview.

Each interview lasted for 30 to 45 minutes, based on the informants' willingness and availability. All the interviews took place between $4^{\text {th }}$ of July and $26^{\text {th }}$ of August in 2009. 
Each interview was conducted in a comfortable room either before or after class time and in accordance with the informants' wishes.. At the beginning of each interview, the participants were asked to provide background information about their names, cultural backgrounds, first language, occupations, number of years in Oman and motivation for learning Arabic. The interviewer did not proceed with the questions in the order prepared beforehand, but $\mathrm{s} / \mathrm{he}$ modified the order and wording of the questions to provide more clarity and to provoke further information. More questions were added to the second interview as per participants' comments in the first interview.

All the interviews were conducted in English which was either the informants' first or second language. The researcher refrained from using Arabic as a language for the interviews since the students were at level three and they would not have been able to express their thoughts fluently and accurately in Arabic. The participants' consent was obtained to audio-tape the interviews and the interviews were followed by a verbatim transcription.

\subsubsection{Learners' Diaries}

In order to triangulate the data and to further support the information gained from the interviews, students' diaries were utilized to gain further understanding of their communication difficulties. Diaries are seen as valuable research tool because they provide access into participants' daily life (Nesic, 2017) and are also believed to offer authentic evidence about how individuals perceive the world around them (Nesic, 2017; Wallin, Adawi, \& Gold, 2016).

As in the interviews, the participants wrote their diaries in English since it was their first or second language and because their level of Arabic was not good enough to allow them to provide complex written or spoken accounts. They were given clear instructions to guide their diary writing. They were asked to write about any speaking activities in or outside school and to express the difficulties they encountered whenever they intended to converse in Arabic. The students were asked to write their diaries during a 10 week course and to submit what they wrote on a weekly basis. Regular meetings were arranged with the study participants to check if they were having any hardship with the diary writing. These meetings were held at the school during break time.

\section{Data Analysis}

Following the coding procedures proposed by Chowdhury (2015), the collected data were manually analysed. Firstly, the data obtained from the interviews and diaries were read several times looking for instances of communication difficulties. Subsequently, the researcher highlighted the communication difficulties, summarized them in concise phrases, and recorded them on a separate sheet. Then the list of difficulties extracted from each individual interview and diary was created and compared to those of other individuals. This was followed by a comparison of the similarities and differences of the communication difficulties. This step was necessary to understand how similar and/or different learners perceive their challenges when learning to speak in Arabic. Finally, a preliminary list of 
learners' communication difficulties was developed and then checked by a colleague whose comments were taken into consideration to finalize the categorization of learners' communication challenges (see Figure 1).

\section{Speaking Difficulties}

The findings showed that the 19 participants had one or more of four speaking difficulties including: putting thought into words, continuous speaking, pronunciation, and applying grammar in their speech. These difficulties are presented in Figure (1).

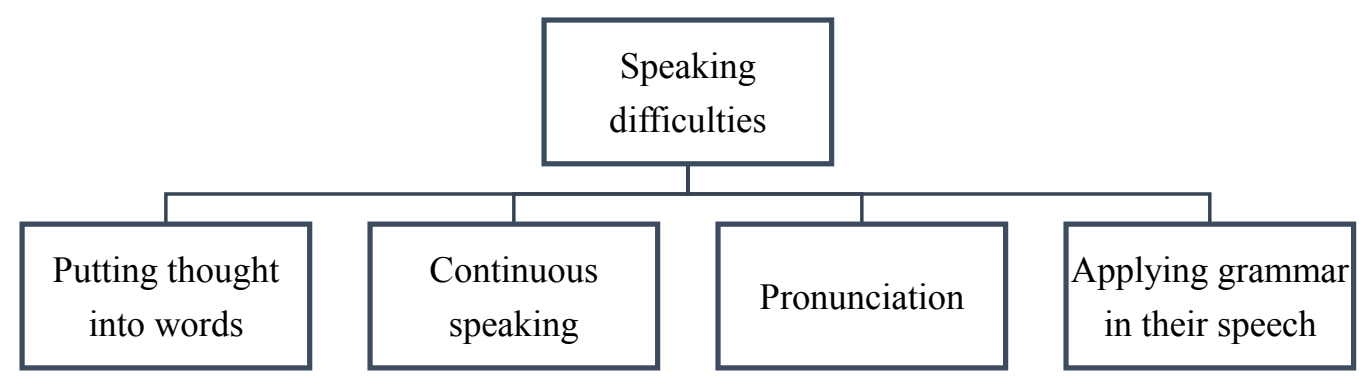

Figure 1. Speaking Difficulties

\subsection{Putting Thought into Words}

Inability to transfer thoughts to the Arabic spoken language is a chief difficulty reported by the majority of these participants. For example, some of them stated that, although they spent months trying to build up their vocabulary, they were still unable to express themselves. Robert said:

"When I want to talk I feel I don't know how I should say it and how to make the right meaning ... it is actually frustrating” (Robert, Interview).

Another participant also reported this difficulty in her diary by stating:

"The hardest part for me actually is trying to say something... when I hear I might understand, but building a meaningful expression is quite difficult" (Linda, Diary).

The existence of this difficulty might be associated with a lack of language input such as vocabulary, commonly used phrases and the general grammar structures of Arabic, or of the idiosyncrasies of the Omani dialect. Although these participants are at an intermediate level of learning and thus should have a basic knowledge that would help them to express themselves, the fact that they are studying Standard Arabic in the classroom, which is to some extent irrelevant to real comprehension and communication, has limited their linguistic competence and, therefore, they found it hard to express their thoughts in the Omani dialect. Researchers in the field of teaching Arabic as a foreign language (TAFL) such as Raish (2015) and Dweik and AL-Shallakh (2015) argue that colloquial varieties are one of the main reasons that can hinder the communication competence of Arabic language learners. 
The difficulty might also result from the lack of opportunities of interacting with people or practising the language in the classroom setting. Many participants reported that they have difficulty in getting the public to speak Arabic to them, including their colleagues and friends who insist on using English. Krashen (2009) has stated with regard to his "Input Hypothesis" that the only way in which learners can acquire language is through comprehensible input which is slightly above the learner's level. According to Krashen, the primary method of getting comprehensible input is through listening or reading. In the case of these learners, the majority of them had not started to read in Arabic yet. Even those who had started to do so seemed to be at a level that did not help them to know how to use the reading input in spoken language or to make a link between reading and speaking. This is because the reading input does not correspond, or only corresponds in a small way, to daily conversations (Madkour, 2007).

Analysis of the data also revealed that this difficulty occurs with some students when they have to say something in an unfamiliar setting, like attending an Omani wedding or other traditional event. For example, Joseph explained:

"I can only speak what I know... these common phrases that my friends use on a daily basis...if I have to talk about something I never heard about, I just stay silent" (Joseph, Interview).

Lillian also said:

"The other day for example, I went to Salem's wedding... it was so funny, I could not say anything. It was so depressing, you know..." (Lillian, Interview).

Some of these participants appear to be able to speak Arabic when the situation requires the familiar phrases which they are used to hearing in daily conversation, but not those phrases more related to cultural expressions and contextual language meaning. This can be understood if we consider that these participants learnt the spoken language either by interacting with their colleagues or while doing their shopping. These interactions enabled them to have routine conversations on commonplace matters but they have had very limited opportunities to understand more complex social situations that require other types of language. Researchers such as Haron (2013), Almelhes (2016), Albirini and Chakrani (2017), Dajani (2015) and Dajani et al. (2014) have argued that, to be able to interact with the public, learners of Arabic not only need to learn the grammar, pronunciation and vocabulary of Standard Arabic, but also to reach pragmatic competence along with linguistic competence so as to be familiar with expressions they can use in different real life events.

Finally, this difficulty could be related to the quality of courses they are studying in Oman or that they have studied before. For example, Abdullah explained how the quality of courses he previously took in his country had impacted his speaking ability.

"I learned Standard Arabic for almost two years in Turkey. To some extent I can read in Arabic but speaking is always a problem for me. I came to be in this situation because I always thought we would do some speaking in the classroom but again we always focus on the grammar and vocabulary related to Standard Arabic. Now I would 
really like to learn how to speak conversational Arabic... I would like to achieve the freedom of speaking with the people who I currently can't understand...." (Abdullah, Interview).

Although this participant has some experience in reading and writing Arabic, using the spoken language was difficult for him. Two years of learning Standard Arabic did not help him to understand what people were trying to say to him nor did it assist him in responding to what they were saying to him. This finding is in line with Palmer (2007) and Carroll, and Al Kahwaji and Litz (2017), who found that teaching learners of Arabic only the standard form has led even the more advanced students to experience a disconnection between their classroom achievement and their lack of ability to integrate linguistically and culturally into Arab society. In addition, Al-Zahrani (2013) found that learners who have only studied this 'high variety' are kept outside society and often experience disappointment and embarrassment when trying to converse with Arabic speakers. Similarly, foreigners speaking formal Arabic language are being "snickered" at by Arab native-speakers, causing them a sense of discomfort and embarrassment (Palmer, 2007, p. 112).

\subsection{Continuous Speaking}

Some participants also reported that, although they could speak to some extent, their main problems were that during the speaking process they found themselves hesitating a lot, and they were sometimes unable to continue the conversation. One of them explained this by saying:

"Even if I can say few things, it is not always easy to carry on my speech. I hold back a lot, and need to stop and think how I should say that..." (Ana, Interview).

Another participant said:

"My problem is that sometimes I try to say something but I am not quite confident about the appropriate words to use so I feel a bit uncomfortable and sometimes I even feel confused. I need to stop because I don't know how to say what I want to say" (Linda, Interview).

Although these participants tried to make conversations with the public, they became frustrated in the middle of speaking and they were unable to carry on their conversation. This might be because these learners still lacked the phrases and the words needed to express the right meaning. Another possible explanation might be that, during the conversation process, the words did not come immediately to their minds as they needed time to recall the right word to use. This might again be related to the lack of practising the local language on a regular daily basis.

It is also possible that these participants are under pressure because of their inability to reply to what has been said to them. In other words, they might be anxious about not completely understanding what the Omani speaker had said or not being able to formulate the correct response combining correct grammar with an understandable accent. All these factors might make them nervous and therefore, "the words disappeared when faced with real life 
situations" (Sally, Interview).

An interesting point regarding the difficulty of 'continuous speaking' was reported by two participants (Lillian and Henry). Lillian stated:

"Sometimes if I speak I need to think a lot you know, does this sound right? Does this not sound right? Do I pronounce it o.k. It's like being uncertain you know..." (Lillian, Interview).

These participants reported that their hesitation during conversation resulted from their attempts to monitor the vocabulary, grammar and pronunciation they were using while communicating with others. Although such behaviours might, to some extent, reflect the use of the 'self-monitoring strategy', according to these participants, this has led them "to be removed from the ability to speak freely because [they] cannot focus on two things at the same time" (Henry, interview). Although previous research (see review of Liu, 2010) has shown the importance of self-monitoring, it seems that applying such a strategy during the speaking process could cause some participants pressure and anxiety which distracts them from their speaking skills. This could prove that it is significant not only to apply a strategy, but also to consider how and when that strategy should be applied and what other supportive strategies might be involved to get more advantage out of its application.

\subsection{Pronunciation}

The majority of the participants reported that their main difficulty in speaking was not being able to pronounce some Arabic sounds correctly. This view is exemplified by the following responses:

“...Arabic sounds are extremely hard ... I have difficulty with $(\tau / \hbar /$ and $\dot{\varepsilon} / \dot{g} /)$. It is really the most difficult sound I have ever experienced..." (Sally, Diary).

"I have a pronunciation problem ... some sounds I cannot make, they never come out correctly, like for example ( $(\vec{h} /)$ ), the sound is coming from your throat, it is difficult because we are not used to that type of pronunciation. It is as if your mouth has been trained all your life to speak one away and to move it to another is very difficult" (Robert, Interview).

The difficulty of pronunciation among Arabic learners has been widely reported by many researchers in the field (see for example, Almelhes, 2016; Hansen, 2010; Shehata, 2017), who argue that the sound system is much more complicated to teach to adult learners than for younger learners. This difficulty probably results from the differences between these participants' first/second or any other languages they had learnt and Arabic. For example, the Arabic phonological systems not only widely vary from other languages in the range of sounds used, but also in the comparative significance of vowels and consonants in expressing meaning. Arabic, for instance, has some sounds which do not appear in other languages such

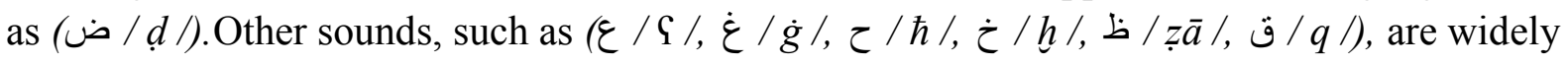
reported to be very difficult for non-native speakers of Arabic (Almelhes, 2016; Hansen, 2010). Another possible explanation is that Arabic teachers do not give much attention to the 
physical aspects of sound production in the classroom setting or do not locate these sounds within the IPA system which could help learners in pronouncing sounds that they do not have in their languages. Almelhes (2016) reported that using a phonetic training system with the learners could ease this difficulty.

The problems of pronunciation among these learners appear to cause another dilemma for those who are conscientious enough to carry on their attempts at speaking, despite their pronunciation problems. They stated that, although they tried to make an effort to create dialogue with people, they found it is very difficult to make the people understand what they were saying. They also reported that Omanis often had trouble understanding their pronunciation and they were often asked to repeat what they had said. For example, Sandra explained this issue by saying:

"I like to converse with the public. I like to make dialogue with them but they very often have difficulty understanding what I have said. It seems like they have their own way of saying the things which I couldn't bring it out" (Sandra, Interview).

This was confirmed by another participant who wrote in her diary:

"It amazed me very much how hard it was, how difficult it was to make people follow me in things that I have said. They asked me to say it again but they couldn't get that either" (Sally, Diary).

It is very likely that this inability to make oneself understood results from different factors. While speaking, these participants might mix up different Arabic sounds or they might use something similar to the target sounds which could give a different meaning. For example,

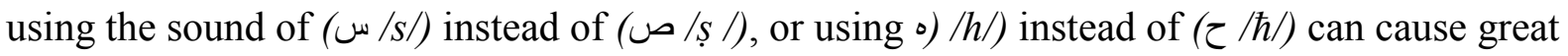
problems in getting people to understand what is meant.

This difficulty might also result from lack of knowledge of the importance of stress in words and sentences. In spoken Arabic, for example, some syllables need to have emphasis in order to make the meaning clear and compressible. Therefore, since Arabic is a stress-timed language, these learners might have problems in grasping the unpredictable nature of Arabic word stress, which can alter meaning.

This problem might also result from the differences in pronunciation between Standard Arabic and spoken Arabic. Some of these participants might not know how to differentiate between Standard Arabic pronunciation and that used in colloquial spoken Arabic. There is no doubt that mixing these codes while talking to the public might lead to misunderstanding. For example, Susan, who had experience of learning Standard Arabic in her country, reported that the use of the Arabic endings 'Dhamma', 'Kasrah', 'Fathah' while speaking led people to have problems with understanding what she said:

"It was a long time before I noticed that using the Arabic ending; Dhamma, Kasrah, and Fathah in spoken Arabic does not make any sense. It was confusing to use them because people could not recognise what I meant... Later on, I knew that in spoken language, these are often left off" (Susan, Interview). 
Similarly, this problem might also be associated with the different dialects used in different Arab countries. For example, Sally, Linda and Neil, had all worked in other Arab countries and could speak the dialects of those countries (Libya, Egypt, Lebanon and Morocco) stated that their past experience in learning other Arabic dialects had led to some confusion when speaking to Omanis. Although some of the participants in this study found 'switching to a different dialect" an effective strategy that helped them to continue their conversations, three participants found that using words and expressions from other Arab dialects led to a break-down in the communication between them and the Omanis:

"When I use the Arabic I have learnt in Morocco, nobody can make out what I am talking about" (Linda, interview).

Sally also confirmed this and said:

"I can somehow speak Egyptian Arabic but people here seem to show that they do not recognize it, or they don't tend to use that word or they might have their own way of using it" (Sally, Interview).

Although these participants live in Muscat and communicate with Omanis who are well-educated and who have a good knowledge of the high Standard Arabic and of the other dialects used in other Arab countries, it might be the way these participants pronounce the words that makes understanding very difficult. Additionally, it is well known that, in the Arab world, if someone from Morocco, for instance, speaks his local language with an Omani, the latter might have difficulty understanding him/her though both of them are Arabs. This could also be applicable to other Arab countries. (see Cote 2009, Harrat et al., 2015).

Unfortunately, this phenomenon seemed to cause some emotional challenges, and these led some participants to avoid speaking in Arabic and to just use English. One of them explained this issue by saying:

"I use English; I think it is easier to use English... I found people having difficulty understanding my Arabic and I do not want to keep bothering them listening to my messy Arabic" (Joseph, Interview).

It might be important to report here that pronunciation difficulties were not been mentioned considered by the four Muslim learners who had studied the Holy Quran in their childhood. My interpretation of this is that some Islamic countries use Arabic with children in their schools for Islamic purposes. Additionally, in some countries such as India and Pakistan, Muslim children are required to attend evening schools to learn how to read the Holy Quran and other Islamic texts. The Muslim participants in this study stated that their childhood experience of learning the Holy Quran and other texts related to Islam helped them in pronouncing the sounds that appeared to be difficult for their classmates. An example of this is given below:

"I am quite good at pronunciation alhamdulilah [thanks to God] Arabic pronunciation was taught to us when I was a child,...I use to go to the Maddrasa [school] to learn the Quran... at that time our teacher trained us how to pronounce these types of sounds 
$\varepsilon / \mathrm{G} /$, غ / $\dot{\mathrm{g}} /$, so I have no problem in speaking them" (Mohammed, interview).

This might support previous research which has consistently demonstrated that, although adolescents and adults are able to communicate in the target languages more quickly than children in the early stages, children may have an advantage in achieving native-like fluency as they have the potential to learn the pronunciation of foreign languages much more easily than adult learners (Saville-Troike \& Barto, 2016).

\subsection{Applying the Grammar in Speech}

The majority of the participants reported difficulty in applying grammar rules to their speaking. They stated that, although they understood some of the Arabic grammar that they had learnt in the course, they very often found it difficult to remember the rules during the speaking process. For example, one of them said:

"The most difficult thing is to be able to use the grammar. It seems that there are still many rules that I need to know to be able to converse... and even if I know some of them like different forms of conjugation, I find it is very difficult to put them in my speech"(Neil, Interview).

Sandra also confirmed this difficulty by complaining:

"Grammar is so frustrating; it is really difficult for me; to know how to apply all the complex rules when speaking such as differences between male and female. I very often mix these up (Sandra, Interview).

This difficulty might be the outcome of the teaching methodology that puts more emphasis on learning grammar, instead of considering it as a skill that should be offered through the four language skills: reading, writing, speaking and listening, rather than as a discrete skill. Researchers such as Mart (2013) and VanPatten (2018) argue that there is no benefit of teaching grammar as static knowledge if the learners are able to recite all the rules of grammar but are unable to apply them in their speaking and writing. They explain that the goal of teaching grammar for students is to be able to use grammar in a meaningful manner.

It is also possible that the diglossic phenomenon of the Arabic language is one source of the problem of grammar. In other words, these participants might find it a paramount challenge to apply the grammar of Standard Arabic in spoken language. Although the structure of Arabic grammar of both varieties might appear similar, there are some specific rules that are used only in Standard Arabic, like the 'case ending' 'التنوين', and they are regularly ignored in speaking, just for the ease of speech.

Another possible reason for this difficulty might be that the informants in this study were still not very familiar with some unique Arabic grammatical rules, especially those which do not appear in the majority of Indo-European languages. For example, Arabic has different rules for the use of male and female cases which appear in verbs (present, past, and future tenses), nouns, adjectives, singular and plural. The application of these rules in spoken Arabic is, to some extent, also different from Standard Arabic. These differences, if not well understood by the learners, as stated by Al-Busaidi (2015) and AlMelhes (2016), might cause some tension 
while speaking. For example, although an expression such as kifa haluka كيف حالك؛' (how are you) is written with the same spelling in Standard Arabic, it would be pronounced differently, as kifa haloka 'كيفا حالوكا' for male, and kifa haloki حالوكي كيفا' for female. However, in the Omani dialect they would have even more different endings, such as keef halak 'كيف 'كالكي ' كالكي ' for male and kef halitsh 'كيف حالتش' for female. There is no doubt that such complicated issues might lead to a certain lack of confidence when using the language. For example, one of the participants explained this difficulty:

"It is a bit confusing isn't it? We have learnt in the classroom, if I would like to ask someone about his news I should say kifa akhbaruka for a male and kifa akhbaroki for female. What confuses me a lot that there are also different ways to say that in the dialogue. You have to say keaf akhbark for male and keaf akbartesh for female" (Gander, Interview).

\section{Summary of Findings}

Easing the journey of non-native Arabic language students would almost certainly attract more and more people to learn Arabic and choose it as a second language. Consequently, it is easy to understand the logic and value of exploring the difficulties experienced by such learners. Via semi-structured interviews and their diaries, the participants expressed the difficulties they faced trying to communicate in Arabic. The findings revealed that the non-native Arabic learners came across four types of communication problems; putting thought into words, continuous speaking, pronunciation and applying grammar in their speech. Putting thought into words and the inability to maintain continuous speaking interactions represent two challenging areas for non-native Arabic speakers. This might be the result of inadequacy of lexical knowledge, or the gap between what students learn in the classroom and what is actually used outside the classroom. Palmer (2007) regretted that an approach that teaches formal and spoken Arabic is not the current practice in AFL. This researcher would suggest that Arabic programs need to consider integrating the teaching of spoken Arabic if they intend to accommodate their students' needs and desires. Teachers are also advised to provide students with opportunities to practise spoken varieties of Arabic, both inside or outside the classrooms (Aladdin, 2013).

Learners' poor Arabic pronunciation and their inability to apply accurate grammatical structures can be attributed to the type of instruction they receive from their teachers, many of whom lack the necessary knowledge of Arabic pronunciation and grammar pedagogy (Shahata, 2017). This researcher also believes that the types of language learning activities used by students in the classroom may also affect their learning of Arabic pronunciation. Many of these activities lack realistic communicative interaction and they do not support students' attempts to transfer their classroom learning to real life situations. Such difficulties can be explained in the light of a number of factors. The idiosyncrasies of Arabic and a misunderstanding of the cultural aspects related to Omani society both appeared to lead learners to cultural frustration and disappointment. 


\section{Conclusion and Implications}

This paper has explored the difficulties in communication encountered by adult learners of ASL in the Sultanate of Oman. Such difficulties not only appear in the classroom context but also while interacting with Omanis in natural settings. To alleviate learners' difficulties when trying to communicate in Arabic as a second/other language, they need to be introduced to useful strategies to help them become confident and competent speakers. It is therefore recommended that such programmes introduce systematic speaking strategies in order to provide clear and steady guidance for both teachers and students. Griffiths and Cansiz (2015) pinpointed teachers' role in raising learners' awareness of the learning strategies, which involves advising them how to choose such strategies and apply them appropriately in accordance with the learners' individual, social and contextual needs. But what are the most appropriate strategies? This is a question that constitutes a possible, future, area of study in teaching and learning Arabic.

It would be of additional value, moreover, to further investigate the area of communication difficulties by following different research designs or data collection. Observing non-native Arabic learners while they are engaged in conversations in real life situations, analysing their produced language and investigating their non-verbal acts would most probably add another dimension to understanding the issue under scrutiny. It is also imperative that learners pay attention to the differences between Standard Arabic and the Omani dialect. Learners should be taught the unique characteristics of the Arabic language such as its phonology, semantics, syntax, and pragmatics. Lack of knowledge of these features causes both confusion and difficulty in transferring what they have learnt from one medium to another. Further research is needed among other groups of language learners to explore the causes of students' speaking difficulties while learning Arabic in Oman, together with an investigation of the extent to which students' learning levels can affect their speaking competence and to understand learners' attitudes to their speaking problems and how they cope with them.

\section{References}

Aladdin, A. (2013). Demotivating Factors in the Arabic Language Clasroom: What demotivates non-Muslim Malaysian learners when it comes to learning Arabic?. Procedia-Social and Behavioral Sciences, 93, 1652-1657. https://doi.org/10.1016/j.sbspro.2013.10.096

Albirini, A., \& Chakrani, B. (2017). Switching codes and registers: An analysis of heritage Arabic speakers' sociolinguistic competence. International Journal of Bilingualism, 21(3), 317-339. https://doi.org/10.1177/1367006915626587

Al-Busaidi, F. Y. (2015). Arabic in Foreign Language Programmes: Difficulties and Challenges. Journal of Educational and Psychological Studies [JEPS], 9(4), 701-717. https://doi.org/10.24200/jeps.vol9iss4pp701-717

Almelhes, S. (2016). Teaching of Arabic language proficiency (pronunciation) to non-native 
speakers: Designing interventions using ICT. (Unpublished doctoral dissertation). Western Sydney University, Australia.

Al-Zahrani, M. A. A. (2013). A Study on the Impact of Arabic Diglossia on L2 learners of Arabic: Examining Motivation and Perception (Master's Thesis). School of Linguistics, Bangor University Wales, UK. https://dx.doi.org/10.24093/awej/th.190

Awang, N. A., Mohamed, M. H., \& Sulaiman, R. (2013). Enhancing Arabic Speaking Skills among Malay Students through Group Work Activities. International Journal of Humanities and Social Science, 3(21), 212-219.

Bin Samah, R., Puteh-Behak, F., Saad, N. S. M., Ali, S. M., Darmi, R., \& Harun, H. (2016). Effective Methods in Learning Arabic Language as a Foreign Language. Mediterranean Journal of Social Sciences, 7(3), 349. https://doi.org/10.5901/mjss.2016.v7n3p349

Blake, R. J., \& Shiri, S. (2012). Online Arabic language learning: What happens after? L2 Journal, 4(2), 230-246. https://doi.org/10.5070/L24212462

Carroll, K. S., Al Kahwaji, B., \& Litz, D. (2017). Triglossia and promoting Arabic literacy in the United Arab Emirates. Language, Culture and Curriculum, 30(3), 317-332. https://doi.org/10.1080/07908318.2017.1326496

Chowdhury, M. F. (2015). Coding, sorting and sifting of qualitative data analysis: Debates and discussion. Quality \& Quantity, 49(3), 1135-1143. https://doi.org/10.1007/s11135-014-0039-2

Cote, R. A. (2009). Choosing one dialect for the Arabic speaking world: A status planning dilemma. The Arizona Working Papers in Second Language Acquisition and Teaching, $16,75-97$.

Dajani, B. A. S. (2015). Teaching Arabic Language: Towards a New Beginning that Stimulates Creativity. Procedia-Social and Behavioral Sciences, 192, 758-763. https://doi.org/10.1016/j.sbspro.2015.06.086

Dajani, B. A. S., Mubaideen, S., \& Omari, F. M. A. (2014). Difficulties of Learning Arabic for non-native speakers. Procedia-Social and Behavioral Sciences, 114, 919-926. https://doi.org/10.1016/j.sbspro.2013.12.808

Dweik, B. S., \& Abu-Irmies, A. (2015). Learning Arabic Culture by Speakers of Other Languages. International Journal of Education, Learning and Development, 3(3), 109-119.

Dweik, B. S., \& AL-Shallakh, M. (2015). Teaching Arabic for Non-Natives in Jordanian Public Universities: Difficulties and Solutions. American Journal of Educational Science, 1(3), 52-59.

El-Omari, A. H., \& Bataineh, H. M. (2018). Problems of Learning Arabic by Non-Arabic Speaking Children: Diagnosis and Treatment. Journal of Language Teaching and Research, 9(5), 1095-1100. https://doi.org/10.17507/jltr.0905.25 
Griffiths, C., \& Cansiz, G. (2015). Language Learning Strategies: An Holistic View. Studies in Second Language Learning and Teaching, 5(3), 473-493. https://doi.org/10.14746/ss1lt.2015.5.3.7

Hamidin, N. M. (2019). Challenges in teaching and learning Arabic language in secondary school: students', teachers 'and parents' views. e-Bangi, 16(2), 1-14.

Hansen, G. F. (2010). Word recognition in Arabic as a foreign language. The Modern Language Journal, 94(4), 567-581. https://doi.org/10.1111/j.1540-4781.2010.01094.x

Haron, S. C. (2013). The Teaching Methodology of Arabic Speaking Skills: Learners' Perspectives. International Education Studies, 6(2), 55-62. https://doi.org/10.5539/ies.v6n2p55

Haron, S. C., Ahmed, I. H., Mamat, A., Ahmad, W. R. W., \& Rawash, F. M. M. (2016). Challenges in Learning to Speak Arabic. Journal of Education and Practice, 7(24), 80-85.

Harrat, S., Meftouh, K., Abbas, M., Jamoussi, S., Saad, M., \& Smaili, K. (2015). Cross-dialectal arabic processing. International Conference on Intelligent Text Processing and Computational Linguistics (pp. 620-632). Springer, Cham. https://doi.org/10.1007/978-3-319-18111-0_47

Hayes-Harb, R., \& Durham, K. (2016). Native English speakers' perception of Arabic emphatic consonants and the influence of vowel context. Foreign Language Annals, 49(3), 557-572. https://doi.org/10.1111/flan.12217

Krashen, S. D. (2009). The comprehension hypothesis extended. In T. Piske \& M. YoungScholten (Eds.), Input matters in SLA (pp. 81-94). Bristol, England: Multilingual Matters. https://doi.org/10.21832/9781847691118-007

Liu, J. (2010). Language learning strategies and its training model. International Education Studies, 3(3), 100-104. https://doi.org/10.5539/ies.v3n3p100

Madkour, A. (2007). Teaching Arabic as a foreign language. Cairo: Dar Alfikr Al-Arabi

Mart, Ç. T. (2013). Teaching grammar in context: Why and how? Theory and Practice in Language Studies, 3(1), 124-129. https://doi.org/10.4304/tpls.3.1.124-129

Nesic, I. (2017). Insights from students' language learning diaries. Journal of Teaching English for Specific and Academic Purposes, 5(3), 529-544.

Newcomer, K. E., Hatry, H. P., \& Wholey, J. S. (2015). Conducting semi-structured interviews. Handbook of practical program evaluation, New Jersey: Jossey-Bass. https://doi.org/10.1002/9781119171386

Palmer, J. (2007). Arabic diglossia: Teaching only the standard variety is a disservice to students. The Arizona Working Papers in Second Language Acquisition and Teaching, 14, 111-122. 
Poyas, Y., \& Bawardi, B. (2018). Reading literacy in Arabic: What challenges 1st grade teachers face. L1-Educational Studies in Language and Literature, 18, 1-15. https://doi.org/10.17239/L1ESLL-2018.18.01.11

Raish, M. (2015). The acquisition of an Egyptian phonological variant by US students in Cairo. Foreign Language Annals, 48(2), 267-283. https://doi.org/10.1111/flan.12140

Redkin, O., \& Bernikova, O. (2016). Globalization and the Arabic language acquisition. In Proceedings of the 20th World Multi-Conference on Systemics, Cybernetics and Informatics: WMSCI 2016, 5-8 July, Orlando, USA.

Ryding, K. (2006). Teaching Arabic in the United States. In K. Wahba, Z. Taha, \& L. England, (Eds.), Handbook for Arabic language teaching professionals in the 21st century (pp.13-20). Mahwah, New Jersey: Lawrence Erlbaum Associates, Inc.

Saville-Troike, M., \& Barto, K. (2016). Introducing second language acquisition. Cambridge University Press. https://doi.org/10.1017/9781316569832

Shaalan, K., Magdy, M., \& Fahmy, A. (2015). Analysis and feedback of erroneous Arabic verbs. Natural Language Engineering, 21(2), 271-323. https://doi.org/10.1017/S1351324913000223

Shehata, A. (2017). Teaching Arabic pronunciation to non-natives: Cognition and practice. In M. O'Brien \& J. Levis (Eds). Proceedings of the 8th Pronunciation in Second Language Learning and Teaching Conference, ISSN 2380-9566, Calgary, AB, August 2016 (pp. 110-120). Ames, IA: Iowa State University.

Taha, T. A. (2007). Arabic as "a critical-need" foreign language in post-9/11 era: A study of students' attitudes and motivation. Journal of Instructional Psychology, 34(3), 150.

VanPatten, B. (2018). Processing instruction. The TESOL Encyclopedia of English Language Teaching, 1-7. https://doi.org/10.1002/9781118784235.eelt0094

Wallin, P., Adawi, T., \& Gold, J. (2016). Reflective diaries-A tool for promoting and probing student learning. In 12th International CDIO Conference.

Wekke, I. S. (2015). Arabic teaching and learning: A model from Indonesian Muslim minority. Procedia-Social and Behavioral Sciences, 191, 286-290. https://doi.org/10.1016/j.sbspro.2015.04.236

Yaakub, M. B. H. (2012). Teaching Arabic as a second language: An evaluation of key word method effectiveness. Jurnal Teknologi, 46(1), 61-72.

Yani, A., Ahmed, I. S., Sahrir, M. S., Muritala, Y. T., \& Kama, N. (2014). An Analysis on Common Syntactical Errors in an Arabic Speech Discourse: A Case Study in International Islamic University Malaysia. US-China Education Review, 740.

Zielinski, B. W. (2008). The listener: No longer the silent partner in reduced intelligibility. System, 36(1), 69-84. https://doi.org/10.1016/j.system.2007.11.004 


\section{Copyright Disclaimer}

Copyright for this article is retained by the author(s), with first publication rights granted to the journal.

This is an open-access article distributed under the terms and conditions of the Creative Commons Attribution license (http://creativecommons.org/licenses/by/3.0/). 